\title{
Whitewashing Through Film: How Educators Can Use Critical Race Media Literacy to Analyze Hollywood's Adaptation of Angie Thomas' The Hate $U$ Give
}

\author{
Tianna Dowie-Chin \\ Matthew P. S. Cowley \\ Mario Worlds \\ University of Florida \\ U. S. A.
}

\begin{abstract}
Grounded in critical race media literacy (CRML), we contend that a comparison of The Hate $U$ Give novel and adapted film can allow for more nuanced conversations in the classroom regarding the functions of racism in America, including intersectionality and colorism. When comparing these texts, educators should ground their analysis in CRML. CRML is one way that educators can facilitate the engagement of critical analysis around the representation of racialized people in media. We argue that when The Hate $U$ Give was rendered into a film, a number of the changes weakened the novel's counterstory messages around racism and white supremacy.
\end{abstract}

KEYWORDS: Critical race media literacy, critical media literacy, critical race theory, racism, young adult literature

Critical Race Media Literacy

Critical Race Media Analysis of The Hate U Give Adapted Film

The Portrayal of Black Women and Intersectionality

Black Lives Matter and Counterstorytelling

Conclusion

References

Author Contract

Young adult (YA) literature provides opportunities for youth to engage in critical discussions around race and racism (Worlds \& Miller, 2019; Thomas, 2015; Sassi \& Thomas, 2008). Texts that address current issues surrounding race and racism, such as Black Lives Matter, allow teachers to acknowledge the ever present existence of racism (Dixson \& Lynn, 2013). Furthermore, YA can serve as "a powerful tool" "when paired with intentional pedagogical choices" (Worlds \& Miller, 2019). Upon its release in 2017, Angie Thomas' YA novel The Hate U Give debuted on the New York Times bestsellers list and remained there for 50 weeks. In the novel, author Angie Thomas, a Black woman herself, recounts the experience of Starr Carter, a Black teenager, as she deals with the aftermath of witnessing her childhood friend Khalil, a Black male, being killed by a police officer. 
Not only has The Hate $U$ Give become a national bestseller, it has also been used in various educational settings, including high school and college classrooms.

In 2018, The Hate $U$ Give was made into a major motion picture directed by George Tillman with the screenplay written by Audrey Wells. Nevertheless, Hollywood films are made for mass consumption, so it was not a surprise to see how The Hate $U$ Give was altered when it was adapted to a Hollywood film. Tillman, a Black man, has directed other films centered on Black people including Soul Food' and Men of Honor (Buchanan, 2018). The late Audrey Wells, a White woman, was known for writing other Hollywood screenplays for films such as Under the Tuscan Sun (Bahr, 2018). The race of the author of the novel, as well as that of the director and screenwriter of the film, has been emphasized as we acknowledge that all media are made by people, people who are impacted by their social identities (King, 2017; Pimentel \& Busey, 2018; Yosso, 2002). As critical educators, we feel that it is also important for us to present our social identities. Tianna Dowie-Chin is a Black cis-gendered heterosexual woman who has worked as a high school teacher and now works in teacher education. Matthew Cowley is a Black cis-gendered heterosexual man who works as a postsecondary educator. Mario Worlds is a Black cis-gendered heterosexual man who also works in teacher education. As people who bring their own experiences to the text we interact with, we acknowledge that our social identities, mainly as Black people, color our interpretation of these texts.

In this paper, we contend that a comparison of The Hate $U$ Give novel and the adapted film of the same name can allow for critical conversations regarding the functions of racism in America. Furthermore, Pimentel and Busey(2018) push educators to scrutinize Hollywood films as they would any other media source. Hollywood films are filled "with cultural productions of race," yet the sting of racism and its effects are often made dull to appeal to a majority White audience (Pimentel \& Busey, 2018, p.2). Critical race media literacy (CRML) is one way that educators can facilitate the engagement of critical analysis around the representation of racialized people in media (Yosso, 2002). Building upon Yosso's work, King (2017) defines CRML "as a theoretical, conceptual, and methodological strategy to examine how people of color are racialized throughout various media platforms" (King, 2017, p. 36).

When a novel is adapted into a screenplay, it is common to see a number of changes made, as a film is often not able to capture every word written in a novel. When comparing The Hate $U$ Give film to the novel, educators should ground their analysis in critical race media literacy. As the novel was written by a Black woman from the perspective of a Black female teenager, the original text, The Hate $U$ Give novel, serves as a counterstory of police brutality. We offer the comparison of The Hate $U$ Give novel and the adapted film, to reveal how the retelling of a Black girl's experience became distorted as it moved from a Blackauthored narrative to a White-authored narrative. As the screenplay was written by a White woman, some may argue that the film serves as an example of "racial ventriloquism'" (Pimentel \& Busey, 2018, p. 4). Hollywood, like other sites of media production, is controlled by White people; hence, the portrayal of Black people in 
Hollywood productions is often defined by Whites (Pimentel \& Busey, 2018). CRML allows teachers to facilitate discussions around texts, including Hollywood films, in order to help students develop racial literacy through media consumption.

The purpose of this paper is to encourage educators to use critical race media literacy to guide their students in analyzing how Hollywood films adapted from other texts portray people of color. We do this by first defining and outlining CRML and how this framework can be applied to adapted films. Then we use this framework to analyze the film version of The Hate $U$ Give and provide some points of comparison between the film and the novel in order to illustrate how the changes made to the film work to appeal to mass audiences and distort the counterstory message offered through the novel.

\section{Critical Race Media Literacy}

In Yosso's (2002) study on the deficit portrayal of Chicanas/os in the media, she outlined the definition of critical race media literacy. This definition is grounded in critical race theory and Freirian critical literacy process. More specifically, Yosso focuses on CRT in education and lists five main elements: (a) the intercentricity of race and racism, (b) the challenge of dominant ideology, (c) the commitment to social justice, (d) the centrality of experiential knowledge, and (e) the transdisciplinary perspective (p. 53). While these five elements are not new ideas on their own, they work together to challenge racial stereotypes, racism, and the construction of race in the classroom. When used as a framework to analyze media, Yosso argues, critical race theory facilitates the examination of how race and racism influence images of People of Color as presented in media. Furthermore, CRML applies Freire's understanding of literacy to media texts, which include Hollywood films. Freire's critical literacy process "provides students with the tools to 'read the word and the world"' (Yosso, 2002, p. 54). Through reading the word and the world, students are called upon to see both media and the world as texts, texts that are a product of societal power relationships.

Yosso (2002) sees the importance of critical media literacy education for all people who work with people of color including teachers, police officers and social workers. From birth, students are subjected to media images of people of color that are often harmful and distorted, hence the necessity of CRML in the classroom. CRML is not only important for students of color, but for White students as well. Students of color need to be able to critically analyze the stereotypical images offered about them in the media. Additionally, White students must be taught to question the images they receive about people of color. Moreover, through the use of CRLM educators can help students understand that (a) media images are constructed; (b) money drives media production; (c) media is produced by people who bring their own experiences and identities to this production; (d) images, words and sounds are used in media to communicate to viewers; (e) we bring our experiences to our interaction with media; and (f) multiple literacies can be acquired as we learn to be critically media literate (Yosso, 2002). Building on Yosso's (2002) conception of critical race media literacy, King (2017) developed 
five core concepts to critical race media literacy that were altered from the Center for Media Literacy's five core questions to consider when analyzing media. We have adapted these core concepts to assist educators in analyzing adapted films that portray people of color. Table 1 provides these core concepts along with questions for students and teachers to consider as they compare an adapted film to its original text.

Table 1. Key Questions to Consider When Analyzing an Adapted Film for Critical Media Education (Adapted from King, 2017)

\begin{tabular}{|c|c|c|}
\hline Keyword & Core Concepts (Yosso, 2002) & Questions to Consider \\
\hline Authorship & Media Images are constructed & $\begin{array}{l}\text { Who wrote and directed } \\
\text { this adaptation? } \\
\text { What are the racially } \\
\text { constructed messages } \\
\text { conveyed through this } \\
\text { adaptation? }\end{array}$ \\
\hline Format & $\begin{array}{l}\text { Images, words and sounds are used } \\
\text { in media to communicate to viewer }\end{array}$ & $\begin{array}{l}\text { How do the physical } \\
\text { features of the cast of the } \\
\text { film differ from what is } \\
\text { presented in the original } \\
\text { text? } \\
\text { How do images, sounds } \\
\text { and words bring attention } \\
\text { to certain events or } \\
\text { characters? }\end{array}$ \\
\hline Audience & $\begin{array}{l}\text { We bring our experiences to our } \\
\text { interaction with media }\end{array}$ & $\begin{array}{l}\text { How are people of color } \\
\text { racialized in this film? From } \\
\text { whose perspective is the } \\
\text { adaptation being told? } \\
\text { Which audiences does the } \\
\text { adaptation of the text } \\
\text { appeal to? }\end{array}$ \\
\hline Content & Money drives media production & $\begin{array}{l}\text { "What lifestyles, values } \\
\text { and points of view are } \\
\text { represented in, or omitted } \\
\text { from, this message?" } \\
\text { (King, 2017, p. 37) }\end{array}$ \\
\hline
\end{tabular}




\begin{tabular}{|c|c|c|}
\hline Purpose & $\begin{array}{c}\text { Media is produced by people, who } \\
\text { bring their own experiences and } \\
\text { identities to this production }\end{array}$ & $\begin{array}{c}\text { What changes have been } \\
\text { made in the adaptation that } \\
\text { alter the original message } \\
\text { of the text? }\end{array}$ \\
\hline $\begin{array}{c}\text { How is the racialization of } \\
\text { characters different or } \\
\text { similar to what is presented } \\
\text { in the original text? } \\
\text { Which characters are } \\
\text { omitted or changed from } \\
\text { the original text? }\end{array}$ \\
\hline
\end{tabular}

In this paper, we use these CRML-informed questions to critically analyze the differences between The Hate $U$ Give novel and its adapted film. We argue that a critical race media analysis of this film will reveal how the changes made to Thomas' novel work to distort and whitewash, a sort of cultural bleaching, the original message of the text (Gabriel, 1998). In fact, these changes then support a critical race media analysis of media texts that portray people of color, including Hollywood films, as our analysis reveals that these changes are significant and work to maintain "power and profit," rather than challenging White supremacy (Kellner \& Share, 2005). Therefore, using CRML as a framework to analyze the discrepancies between the novel and the film would allow students to engage with these media texts in a way that could allow students to "read' racism through media texts" (King, 2017. p.36).

\section{Critical Race Media Analysis of The Hate U Give Adapted Film}

While the characters of The Hate $U$ Give novel are fictitious, the novel is based on a short story Thomas wrote following the real life murder of Oscar Grant, an unarmed 22-year-old Black man, by a police officer. In an interview with the Los Angeles Times Thomas notes, "I wrote a short story about a boy named Khalil who was a lot like Oscar [Grant] and a girl named Starr who was a lot like me" (Anderson, 2018). Over time Thomas expanded the original short story to The Hate $U$ Give novel, inspired by the similar deaths of other Black people including Trayvon Martin and Sandra Bland, to only name a few. Thomas explains that it was important that this story be told from the perspective of a teenage Black girl, as "we don't discuss the impact it [police brutality] has on Black girls" (Anderson, 2018). Similarly, the hashtag \#SayHerName was created to recognize the limited discussions around Black women, state violence and policing (McMurtry-Chubb, 2015). Through her multiple media interviews around her novel, Thomas has spoken to the intentionality of her work. The Hate $U$ Give novel serves as an intersectional counterstory. Used interchangeably, counternarratives and counterstories are central to critical race theory (Cook \& Dixson, 2013; Huber, 
2008). Critical race theorists Solórzano and Delgado Bernal (2001) describe a number of functions of counterstories including that "they can challenge the perceived wisdom of those at society's center, and they can provide a context to understand and transform established belief systems" (p. 327-328). \#SayHerName challenges the narrative that only Black men are impacted by statesanctioned violence. Along the same lines, The Hate $U$ Give novel serves as a counterstory to anti-Black police brutality, as Thomas (2017) offers Starr's perspective on the killing of her friend Khalil to challenge the dominant narratives on police brutality. Through a CRLM analysis of changes made in the film, we argue that the adapted film did indeed alter the counterstorytelling power of the text and that the film is an example of "racial ventriloquism." We first use CRML to analyze the characterization of two Black women in the film, Starr and her mother, Lisa Carter. Then, we analyze varying aspects of the film that worked to weaken the Black Lives Matter counterstory originally presented in the novel. We believe that this analysis of The Hate $U$ Give film can serve as a guide for educators who seek to support their students in a similar process of analysis.

\section{The Portrayal of Black Women and Intersectionality}

When applying a critical race media analysis to the depictions of Lisa Carter and Starr in the adapted film, we question the purpose of the changes made to these characters and how these changes impact the counterstorytelling power of the text. We consider questions from Table 1 such as how is the racialization of Lisa Carter in the adapted film different from what is presented in the novel and how does critical race theory help us consider racialization of Lisa Carter and Starr? Expanding on CRT's tenet of intersectionality, we home in on the ways that Black women are portrayed in this adapted film, written by a White woman and directed by a Black man. Known for coining the term intersectionality, Crenshaw (1991) presented the term to acknowledge the ways that racism and sexism intersect in the lives of Black women, emphasizing the intragroup differences among Black women and men. Furthermore, Collins and Bilge (2016) emphasize the importance of focusing on what intersectionality does rather than what intersectionality is. In this section of the paper, we focus on the roles of Lisa Carter and her daughter Starr in order to pay particular attention to the treatment of Black women in the adaptation of The Hate $U$ Give, a text that was originally written by a Black woman from the perspective of a Black girl.

\section{The Invisibility of Starr's Mother}

In The Hate U Give film, Starr's mother, Lisa Carter, could be referred to as a minor character, as she is given few lines and is not a central character in the plot of the story. This is in great contrast to Lisa's depiction in the novel. In the novel, Lisa Carter was central to Starr's life and her upbringing. We learn through Starr that her mother is a registered nurse who "told [her] what went where, and what didn't need to go here, there, or any damn where till [she] grown" (Thomas, 2017, p. 28). In fact, in Chapter 15 of the novel, Lisa informs her family that she is 
going for a second interview for a nursing manager position. The family is both excited and happy to learn of her interview as the new job pays "six figures" (Thomas, 2017, p. 320). Conversely, Lisa is rendered nearly invisible in the film, so much so that the interview and job discussion are removed from the story altogether. In Thomas' novel, Lisa eventually obtains the new job, and it is this job that enables the Carters to purchase a new home and move from Garden Heights, a move that is completely altered in the film.

The erasure of Black women/womanhood is not new and supports a Black feminist examination of the portrayal of Lisa Carter in the film. Black feminist scholar Collins (2000) notes that "within U.S culture, racist and sexist ideologies permeate the social structure" so much that we have become used to stereotypical images of Black women as mammies, jezebels and welfare mothers, to name just a few (p. 5). These negative stereotypes of Black women are harmful; they have "been fundamental to Black women's oppression" (Collins, 2000, p. 5). Rather than portraying Lisa as the successful Black woman she was originally written as in the novel, the version of her presented in the film denies her role in her family, particularly her financial role. This erasure plays into a majoritarian narrative that fails to recognize the labor of Black women (Collins, 2000): Black feminism calls for "documenting Black women's labor market status in order to see the general patterns of race and gender inequality" (p. 45). Even though Lisa is married to Maverick Carter, the Carter family as presented by Thomas differs in function from the traditional White-male-dominated home. In the novel, both Maverick and Lisa are fundamental to Starr's upbringing and their characters were presented with depth. Both Lisa and Maverick contributed to their home financially. Collins (2000) notes the significance of this historically: "Many [Black] women tried to leave the paid labor force," though "the limited opportunities available to African-American men made it virtually impossible for the majority of Black families to survive on Black male wages alone" (p. 54). Without critical analysis grounded in critical race theory, Lisa Carter's characterization could be overlooked and dismissed. CRML allows educators to guide students to question why Lisa Carter's presentation in the film differs from what is presented in the text and how this representation is problematic.

\section{Starr's Skin Complexion}

It should be noted that we find the performance of Amandla Stenberg as Starr to be gripping, emotional, and laudable. Notwithstanding this, we focus on the casting of Starr to emphasize another problematic change made in the film. We consider how Starr is racialized in the film and how this compares to her description in the novel. From a CRLM analysis, we submit that the casting of a light-skinned actress to portray Starr, who is depicted as a brown-skinned woman on the cover of the book, and described as "medium-brown" within the novel, is a clear example of colorism, a subversive form of racial oppression hidden within the machinations of racial discrimination that awards advantages to Black Americans based on their "phenotypical proximity to whiteness" (Reece, 2016). In many ways, colorism doubles down on the oppression of racism, as "people of color with dark 
skin tones continue to pay a price for their color, and the light skinned...benefit from their association with whiteness" (Hunter, 2007, p. 249). Indeed, racism bears down upon both lighter-skinned and darker-skinned Black people; however, lighter-skinned people enjoy more privileges than their darker-skinned counterparts. In fact, critical skin theory posits that colorism is a constant feature of American culture, "germane to the social core of Western civilization" (Hall, 2018, p. 2139). Black people with lighter skin are considered to be more employable and are employed at higher rates, incarcerated and disciplined in schools at lower rates, and possess higher representation in positions as corporate executives and government officials (Norwood, 2015). White standards of beauty are learned and internalized by Black people and White people alike, leading to material economic and social differences in the lives of Black people based on skin color (Hunter, 2005). The choice to cast a light-skinned actress as the protagonist of this film is almost expected. We have learned this lesson over several generations, and "the seeds of colonization have grown and thrive, playing a role....in the black consciousness of what is beautiful, what is worthy, what is successful, what is valuable" (Norwood, 2015, p. 605). It is the mundanity of the decision that highlights the pervasiveness of colorism.

For her part, Starr describes her own skin tone in the novel, stating, "As for me, it's as if God mixed my parents' skin tones in a paint bucket to get my mediumbrown complexion" (Thomas, 2017, p. 38). She also describes other characters in the book as light-skinned and dark-skinned, clearly differentiating herself from these descriptors. Additionally, juxtaposing an image of Amandla Stenberg as Starr on the image of Starr on the cover of Thomas' novel raises perceptible differences. Several think pieces, editorials, and blogs were written to discuss the problematic nature of the casting of Stenberg. The artist who designed the book cover, Debra Cartwright, stated that she "was hoping it would be a very brownskinned actress, because there's so little opportunities in these big movies for darker-skinned actresses" ('lllustrator Debra Cartwright', 2018). This desire was not unfounded, as Cartwright asserted that her design "literally just followed exactly what they said in the book" ('Illustrator Debra Cartwright', 2018). Thomas, on the other hand, stated that, "Amandla was cast as Starr before there was a cover. When I was writing the book, I imagined Amandla" ('Illustrator Debra Cartwright', 2018). Critical race media analysis allows us to see the casting of Amandla as Starr as more than an insignificant choice: it underscores Hollywood's preference for lighter skinned actresses (Williams, 2015). The prevalence of light-skin actresses being cast for roles in which the descriptions of the characters indicate a darker skin tone is a pernicious form of anti-Black racism, manifesting as colorism and pitting the Black community against itself in a battle for representation in the media. Darker skin tones are negatively associated with Blackness. By lightening Starr's skin, we are presented with a version of our protagonist that is more attractive to mass audiences. 


\section{Black Lives Matter and Counterstorytelling}

As noted earlier, Thomas' (2017) novel is written from the perspective of Starr, left behind in the wake of the murder of an unarmed Black man by a White law enforcement officer. This book intentionally frames the central tragedy of Khalil's murder to take a stance against police violence. Thomas has stated that she wrote the novel in this way because she believed that she "had a better chance of reaching people who may take issue with the phrase 'black lives matter'[sic]. People who already have their preconceived notions about the movement, about all of it" (Evans, 2017). Solidifying this story's connection to real-world events, some elements of the story are lifted directly from the headlines. For example, Khalil's body is left "lying in the street like it's an exhibit" (Thomas, 2017, p. 31) after his murder. This evokes the images and emotion of Michael Brown's body left on Canfield Drive in Ferguson, Missouri, for nearly four hours without receiving medical treatment (Bosman \& Goldstein, 2014). Again, the novel functions as a counterstory, explicitly concerned with combatting victim-blaming by centering the experiences of Black people with racism and White supremacy (Delgado \& Stefancic, 2017).

Thomas' narrative explicates elements of real-world cases of police violence, which creates a composite counternarrative (Cook \& Dixson, 2013; Solórzano \& Yosso, 2002). Interestingly, the screenplay for Thomas' The Hate $U$ Give diverges from the novel upon which it is based in important ways that ultimately serve to whitewash the novel's aims by creating sympathy for White police officers who have murdered unarmed Black people. While these changes could have been made for myriad reasons, a CRML analysis reveals how these changes alter the story in ways that intentionally situate the perpetrating officers in a sympathetic light. The film retells Thomas' story in a way that shifts the blame and responsibility away from police officers and, consequently, in the direction of the victims of police brutality. Focusing on three key differences between the book- Khalil's death scene, Uncle Carlos' position on Khalil's murder, and the altered ending-- reveals how changes made in the film undercut the salience of the novel's agenda.

The Hate $U$ Give novel is an important counterstory that seeks to illuminate the spirit of the Black Lives Matter movement. However, some of the changes made in the film adaptation serve to blame the victims of police violence for their own predicament. As a result, the audience is pushed to have more empathy for police that use their badge to inflict pain on Black people and their communities.

\section{Khalil's Murder}

Khalil's murder at the hands of a police officer is a central plot point of both the novel and the screenplay. Taking place near the beginning of the story, this tragic event serves as the impetus for everything else that happens within the story. The movie alters the details of Khalil's murder in ways that place the blame for Khalil's murder at his own feet. In both media, Khalil and Starr are pulled over by Officer Brian Cruise, Jr. (or One-Fifteen as Starr calls him) one evening upon 
leaving a house party. After Khalil demands to know why he has been pulled over, he is asked to exit his vehicle. When the police officer returns briefly to his squad car, Khalil decides to check in on the visibly upset Starr. At this moment the film and novel diverge. In the novel, Khalil opens his car door to check on Starr. When One-Fifteen's attention returns to Khalil, he sees an open car door and a hairbrush (that he believes is a handgun) sticking out of the pocket of the door. This leads to the officer's decision to fatally shoot Khalil. In the movie, as Khalil checks in on Starr, he actively searches for a hairbrush through the open car window. He then raises the hairbrush to his own head and brushes it during the traffic stop. Thus, the officer's decision to shoot and kill Khalil in the movie is based on Khalil holding (and moving) a dark object taken from his vehicle at night. This portrayal allows for the blurring of responsibility in ways that are unrealistic, disparaging, and unnecessary. Depicting the murder in this way moves the incident into a gray area where the responsibility for Khalil's murder cannot be placed squarely on the police officer. This shift successfully generates nuance within the public debate over police brutality, but it does so by assigning blame to Khalil for his own murder through largely unrealistic actions.

The public is prone to victim blaming, especially in the case of Black men. The harmful messages that we are given about Black men ask us to accept their subjugation as a result of their own deficiency and delinquency (Weissinger et al., 2017). Critical race theorists remind us that racism is normal and is an integral part of American society (Ladson-Billings, 2016). In an exploration of the tweets that followed the murders of both Eric Garner and Michael Brown, Ramirez and Cole (2018) find that many people "present the incidents of violence against Black men as isolated cases of punishment that they deserved rather than the manifestations of larger social problems and systematic" (p. 401). The movie depiction of the incident allows viewers to believe that Khalil made a conscious decision to wield a dark object taken from his car during a traffic stop. Though Khalil is unarmed in both the film and the novel, the film suggests that Khalil is to blame for his choices. This change distorts Thomas' original story in ways that weaken the message of the text.

\section{Uncle Carlos' Views}

In similar ways, the depiction of Uncle Carlos in the adapted film weakens the counternarrative message of The Hate $U$ Give. In the novel, Uncle Carlos is Starr's beloved uncle as well as a police officer who worked alongside One-Fifteen. When Khalil is killed, we witness Uncle Carlos struggle with his own internalized racial oppression. Having accepted negative representations of Black people fed to him through society and culture (Fanon, 2008), he considers a rumor that Khalil might be a drug dealer and postulates that this may have been why the officer fatally shot him. Starr's father, Maverick, is quick to challenge this assumption, stating that "he thought Khalil was a drug dealer... A thug. Why he assumed that though? What? By looking at Khalil?" (Thomas, 2017, p. 60). Uncle Carlos believes that One-Fifteen is a good person, and defends him against accusations that the murder is racially motivated. In the book, Starr asks her uncle if he would have 
shot Khalil, to which he reluctantly responds, "I'd like to think I wouldn't have, but it's hard to say unless you're in that situation, feeling what that officer is feeling-" (Thomas, 2017, p.133). Uncle Carlos' character highlights the plight of Black law enforcement officers as they balance their personal identity as Black people with their professional identity. The history of racism in the United States ensures that embracing this professional identity is an embracement of White supremacy. These identities come into direct conflict with one another over Khalil's murder. When Starr informs her uncle that One-Fifteen held a gun to her, Uncle Carlos is no longer able to ignore the injustice of the situation. However, in Hollywood's portrayal of the novel, Uncle Carlos' exchange with Starr takes a different turn. Embodying his positionality as a police officer, he walks Starr through the mentality and decision-making processes of a policeman who has pulled someone over at night. He asserts, "We instruct them not to move. But if they open the door, or reach through an open window, they're probably going for a weapon. So, if I think I see a gun, I don't hesitate. I shoot" (Tillman, 2018). Starr challenges his resolve by asking whether he would shoot if the person were White. Unsurprisingly, Uncle Carlos states that if the person were White, he would likely tell them to put their hands up instead of shooting them. While this change does not serve to blame Khalil for his own death, it also does not adequately implicate systemic and internalized racism. Absent a deeper understanding of Uncle Carlos' thinking, the scene appears to seek sympathy for White police officers who are doing nothing different than their Black colleagues would have done. Without discussing the permeance of White supremacy and its ability to employ even the bodies of people of color, the film's commitment to the Black Lives Matter movement is weakened by this moment.

\section{Alternate Ending}

Lastly, we analyze the alternate ending presented in the film using critical race media analysis. In a tense and emotional scene that only appears in the film, Starr's eight-year-old brother Sekani pulls a gun on the leader of a street gang named King in order to protect his family. Moments later the police arrive and draw their weapons. Sekani becomes the embodiment of the film's namesake. Tupac's acronym T.H.U.G. L.I.F.E. stands for "The Hate $U$ Give Little Infants F-ks Everybody," and this moment in the movie carries the full weight of that sentiment. Sekani has watched his sister suffer emotionally after the death of a friend, and he has seen his brother and father suffer both physically and emotionally because of gang violence. He has watched tanks patrol his neighborhood, and he has seen the anger of the Garden Heights community manifest in the form of protests and riots. Images of Tamir Rice, the 12-year-old boy who was killed by police while playing with a toy gun, are invoked at this moment. Starr specifically says, "Look at Sekani, he's the little infant. The result of hate. And he's about to f-k everybody" (Tillman, 2018). Sekani represents the hate given to the Black community turned back on itself. However, the very next lines of the movie succeed in whitewashing the message to which the novel seems committed. Starr states, "It's not the hate you give. It's the hate we give....But we can break the cycle." These lines divert the audience's attention away from state-sanctioned violence and systemic 
racism. The insinuation is that if Sekani were killed in this moment, Black-on-Black crime would be equally as implicated as police violence in his murder.

What about Black-on-Black crime? is a question frequently asked to weaken antiracist arguments. To be sure, gang violence unnecessarily claims far too many lives, but inserting this point in the film places the murder of unarmed Black people on the same level as violence within communities ravaged by racial segregation, poverty, and economic subjugation. Derrick Bell reminds us that this distraction is made possible by the fact that Black-on-Black crime indeed exists, but "no less real is the poverty and hopelessness that underlie so much violent crime" (as cited in Delgado \& Stefancic, 2005, p. 629). In short, even the hate given to Sekani by the Black community is birthed from White supremacy and racism.

\section{Conclusion}

The award-winning novel The Hate $U$ Give, and its eventual screen adaptation, created a unique opportunity for cinematic engagement centered around often difficult discussions about race, racism, and police brutality. While topics of racial inequity being explored through media is not a novel concept, the film's pairing with Thomas' literary work, contextualized within the current political climate, reintroduced to the forefront of America's consciousness much needed conversations about racial inequity and representation in both film and everyday life. Moreover, the juxtaposition of the novel with its reimagined film adaption calls into question the cinematic responsibility of screenwriters and producers to portray people of color and their lived experiences in a way that is accurate and true, as opposed to stories that are more palatable for White viewership.

There is little expectation that White screenwriters writing about Black life would value accurate representation beyond its profitability. Black pain and suffering have undoubtedly produced tremendous economic benefits within the film and media industry. Additionally, Hollywood is seemingly, if not absolutely, committed to upholding White supremacy through film. As a result, the reimaging of characters of color during film adaptation is frequently problematic at best and destructive at worst. Left unchallenged, media texts such as film have the ability to reinforce racial stereotypes and maintain White supremacist ideals. Critical race media literacy, then, offers a theoretical framework that educators can use to help students critically examine films that explore issues of race and racial representation.

Critical media literacy is particularly important for educators, because facilitating discussions that address race and racism can be both difficult and dangerous for a number of reasons. Some teachers might feel compelled to analyze films such as The Hate $U$ Give from a color-blind perspective that fails to recognize and name the explicit role that race plays in shaping the characters' experiences. This approach makes it possible to ignore the significance of many of the changes from the novel to the film adaptation and what that means for how viewers come to understand how race functions within our society, especially concerning interactions between People of Color and law enforcement. CRML, 
however, helps students begin to think more critically about the production of film and understand and challenge implicit biases and underlying intentions and messages seen throughout Hollywood movies and films.

As teachers begin to prepare students to be able to view texts (film and written text) as windows through which we can examine the world, students will need to develop their own critical literacies. The goal of critical literacy is to help students learn to challenge dominant discourses and ways of reading the world through written text (Lewison et al., 2002). Critical media literacy builds on this foundation and provides a new medium for students to apply critical skills. Thomas, a Black woman, penned The Hate $U$ Give centering the experience of Starr, a young Black girl, dealing with the ramifications of police brutality. This counterstory underscores the importance of both the \#BlackLivesMatter and \#SayHerName movements. Both movements, which were started by Black women, challenge dominant narratives about police brutality and seek justice for Black people. However, when the text is rendered into a Hollywood film, the counterstory is distorted. A critical race media analysis of The Hate $U$ Give novel and film underscores the importance of texts written by Black women about Black women. We offer our analysis of The Hate $U$ Give texts to support educators engaging in this type of analysis with their students. Teachers and teacher educators alike can use the key questions provided in Table 1 to facilitate the comparison of an original text to its adapted film. A CRML analysis allows students to critically challenge what is presented to them through film. In doing so, they become critical consumers of films who are better able to understand the world(s) they live in and how the whitewashing of films relates to many of their daily experiences with race.

\section{References}

Anderson, T. (2018, August 30). How the deaths of Oscar Grant and Trayvon Martin inspired 'The Hate U Give.' Los Angeles Times. https://www.latimes.com/entertainment/movies/la-ca-mn-sneaks-hate-ugive-20180830-story.html

Bahr, L. (2018, October 5). 'The Hate U Give' screenwriter Audrey Wells dies at 58. Associated Press News. https://apnews.com/af55760460894c03829fd2b3150ba620/'The-Hate-UGive'-screenwriter-Audrey-Wells-dies-at-58

Bosman, J., \& Goldstein, J. (2014, August 23). Timeline for a body: 4 hours in the middle of a Ferguson Street. New York Times. https://www.nytimes.com/2014/08/24/us/michael-brown-a-bodys-timeline4-hours-on-a-ferguson-street.html

Buchanan, K. (2018, October 18). "With one strong word, 'The Hate U Give' couldn't hold its tongue." New York Times. https://www.nytimes.com/2018/10/18/movies/the-hate-u-giveexpletive.html 
Collins, P. H. (2000). Black feminist thought: Knowledge, consciousness, and the politics of empowerment (2nd ed.). Routledge.

Collins, P.H., \& Bilge, S. (2016). Intersectionality. Polity Press.

Cook, D. A., \& Dixson, A. D. (2013). Writing critical race theory and method: A composite counterstory on the experiences of Black teachers in New Orleans Post-Katrina. International Journal of Qualitative Studies in Education (QSE), 26(10), 1238-1258.

Crenshaw, K. (1991). Mapping the margins: Intersectionality, identity politics, and violence against women of color. Stanford Law Review, 43(6), 1241-1299.

Delgado, R., \& Stefancic, J. (Eds.). (2005). The Derrick Bell reader. New York University Press.

Delgado, R., \& Stefancic, J. (2017). Critical race theory: An introduction (3rd ed.). New York University Press.

Dixson, A. D., \& Lynn, M. (2013). Introduction. In A. D. Dixson \& M. Lynn (Eds.), Handbook of critical race theory in education (pp. 1-6). Routledge.

Evans, D. (2017, March 20). Talking with Angie Thomas, author of the best-selling YA novel inspired by Black Lives Matter. The Cut. https://www.thecut.com/2017/03/angie-thomas-the-hate-u-give-interviewya-novel.html

Fanon, F. (2008). Black skin, white masks (1st ed.) Grove Press.

Gabriel, J. (1998). Whitewash : Racialized politics and the media. Routledge.

Hall, R. E. (2018). The globalization of light skin colorism: From critical race to critical skin theory. American Behavioral Scientist, 62(14), 2133-2145. https://doi.org/10.1177/0002764218810755

Huber, L. P. (2008). Building critical race methodologies in educational research: A research note on critical race testimonio. FIU Law Review, 4(1), 159-173.

Hunter, M. L. (2007). The persistent problem of colorism: Skin tone, status, and inequality. Sociology Compass, 1(1), 237-254.

\section{https://doi.org/10.1111/j.1751-9020.2007.00006.x}

Hunter, M. L. (2005). Race, gender, and the politics of skin tone. Routledge.

Kellner, D. \& Share, J. (2005). Toward critical media literacy: Core concepts, debates, organizations, and policy. Discourse: Studies in the Cultural Politics of Education, 26(3), 369-386.

King, L. J. (2017). The media and black masculinity: Looking at the media through race[d] lenses. Critical Education, 8(2), 31-40.

Ladson-Billings, G. (2016) Critical race theory--What it is not! In A. D. Dixson \& M. Lynn (Eds.), Handbook of critical race theory in education (pp. 1-6). Routledge. 
Lewison, M., Flint, A., \& Sluys, K. (2022). Taking on the journey of critical literacy: Newcomers and novices. Language Arts, 79(5), 382-392.

McMurtry-Chubb, T. A. (2015). SayHerName \#BlackWomensLivesMatter: State violence in policing the Black female body. Mercer Law Review, 67(3), 651706.

Norwood, K.J. (2015). "If you is white, you's alright...": Stories about colorism in America. Washington University Global Studies Law Review, 14(4), 585607.

Reece, R. L. (2016). What are you mixed with: The effect of multiracial identification on perceived attractiveness. Review of Black Political Economy, 43(2), 139-147.

Sassi, K., \& Thomas, E.E. (2008). Walking the talk: Examining privilege and race in a ninth-grade classroom. The English Journal, 97(6), 25-3.

Solórzano, D., \& Delgado Bernal, D. (2001). Examining transformational resistance through a critical race and Latcrit theory framework--Chicana and Chicano students in an urban context. Urban Education, 36(3), 308342.

Solorzano, D. \& Yosso, T. (2002). Critical race methodology: Counter-Storytelling as an analytical framework for education research. Qualitative Inquiry, 8(1), 23-44. https://doi.org/10.1177/1077800402008001003

The Hate U Give: Illustrator Debra Cartwright 'wasn't thrilled' about casting. (2018, August 03). BBC News. https://www.bbc.com/news/entertainment-arts45056257

Thomas, A. (2017). The hate $u$ give (1st ed.). Balzer + Bray, an imprint of HarperCollinsPublishers.

Thomas, E.E. (2015). "We always talk about race": Navigating race talk dilemmas in the teaching of literature. Research in the Teaching of English, 50(2), 154-175.

Tillman, G., Jr. (Director). (2018). The Hate U Give [Motion picture]. United States: 20th Century Fox.

Pimentel, C. N., \& Busey, C. L.. (2018). Hollywood films as social studies curriculum: Advancing a critical media literacy approach to analyzing Black male representation. Critical Education, 9(4), 1-17.

Weissinger, S. E., Mack, D., \& Watson, E. (2017). Violence against black bodies: An intersectional analysis of how black lives continue to matter. Routledge.

Williams, S. (2015, February 5). Alexandra Shipp, colorism and casting the perfect Storm. Rolling Out. https://rollingout.com/2015/02/05/alexandra-shippcolorism-casting-perfect-storm/

Worlds, M., \& Miller, C. (2019). Miles Morales: Spider-Man and reimagining the canon for racial justice. English Journal, 108(4), 43-50. 
Yosso, T. J. (2002) Critical race media literacy: Challenging deficit discourse about Chicanas/os. Journal of Popular Film and Television, 30(1), 52-62.

\section{Author Contact}

Tianna Dowie-Chin, tdowiechin@ufl.edu

School of Teaching and Learning

College of Education

1-235C Norman Hall

PO Box 117042

Gainesville, FL 32611-7044

Matthew P.S. Cowley, matthewpaulc@ufl.edu

School of Teaching and Learning

College of Education

1-235C Norman Hall

PO Box 117042

Gainesville, FL 32611-7044

Mario Worlds, mareaszy@ufl.edu

School of Teaching and Learning

College of Education

1-235C Norman Hall

PO Box 117042

Gainesville, FL 32611-7044 